\title{
Pit Lake Water Quality Prediction: Uncertainty and Utility
}

\author{
T. MEUZELAAR ${ }^{1 *}$
}

${ }^{1}$ Life Cycle Geo, LLC., Lakewood CO 80228

(*correspondence: tom@lifecyclegeo.com)

\section{Uncertainty in Pit Lake Water Quality Prediction}

Predictions of mine pit lake water quality typically require conceptualization and input from a variety of disciplines, including geochemistry, geology, hydrology, hydrogeology, limnology, and mine engineering. Such predictions are a requirement during the early mine permitting stages, when little data are available. As such, differences between permitting stage predictions and actual operational and post-closure water quality are often several orders of magnitude for relevant constituents.

Herein we explore this uncertainty using post-closure pit lake model predictions for the Bear Lodge REE project in NE Wyoming (USA), recently awarded a draft EIS. Post-closure pit lake water quality is deemed primarily a function of mass loading resulting from subflow interaction with the pit wall and blast-impacted fracture zone. The extent of infiltration, amount of available reactive surface area, and rate of soluble product build-up are extremely difficult to quantify at this stage as is the rate of mass loading, derived from laboratoryscale leach testing. Various scaling factors are employed to address this uncertainty. Pit lake $\mathrm{CO}_{2}$ levels, radium coprecipitation, various water balance and limnological aspects represent areas of additional uncertainty.

\section{Utility of Permitting Stage Water Quality Predictions}

Despite significant inherent uncertainty, permitting mine life cycle stage predictions are highly useful in that they:

1. Initiate regular, vital engagement between operators and all project stakeholders (e.g. regulatory)

2. Force critical thinking about and development of a the site conceptual model

3. Lead to early identification of knowledge gaps, which drives investigation in later project stages

4. Result in lower long-term project costs by identifying mitigations that are more cost-effective to implement proactively, rather than reactively

5. Identify constituents requiring diligent monitoring, field-scale testing and regulatory conditions to progressively lower uncertainty as mining proceeds. Such predictions are an essential step in the modern mine life cycle that includes subsequent data gathering and continuous model improvement. Modern sensors combined with machine learning technology present a more accurate and efficient predictive alternative to empirical, process-based models. 